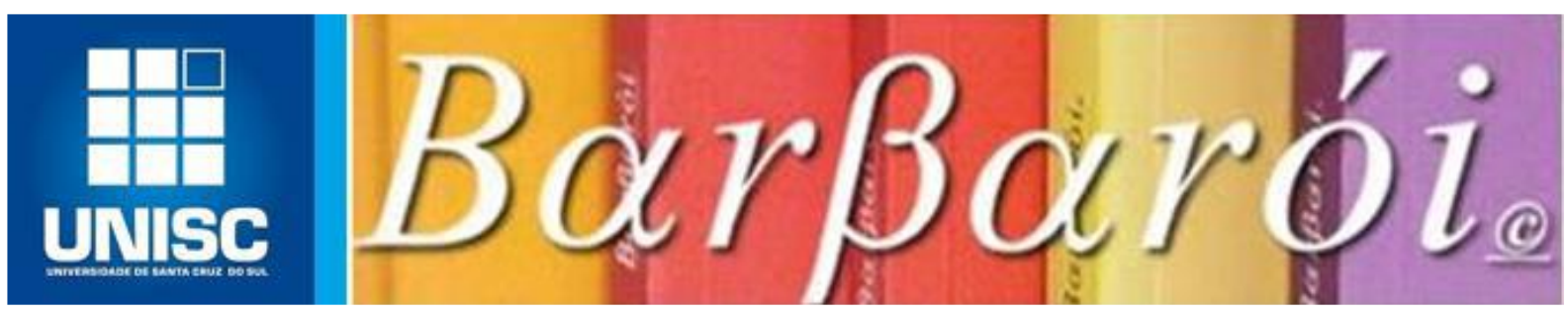

\title{
PARAGUAY, ¿EL RENACER DE UNA UTOPÍA CONTAGIOSA?
}

DOI: http://dx.doi.org/10.17058/barbaroi.v0i58.16184

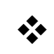 \\ Jorge Coronel Prosman \\ Paraguay

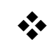

\section{Resumo}

El artículo analiza las movilizaciones políticas en Paraguay, a partir de la década de 2000, con mayor atención a la relación entre los movimientos sociales y el gobierno de Fernando Lugo (2008 - 2012). Entre los aspectos que destaca el texto está que los movimientos sociales en Paraguay tuvieron un rol significativo desde la década del 2000. Desde la llegada de Lugo al gobierno nacional, sin embargo, se observó que las acciones de los líderes de las Centrales Sindicales comenzaron a priorizar las posiciones gubernamentales. Es decir, los partidos y agrupaciones de izquierda apuestan por el fortalecimiento de organizaciones populares, sindicatos, movimientos sociales partiendo del supuesto de que la vía administrativa podría fortalecer las organizaciones y garantizar mayores ganancias de derechos. Lo que sucedió, sin embargo, fue que los líderes fueron rápidamente cooptados por la lógica del poder estatal y la ocupación de cargos se convirtió en el objetivo principal.

Palabras clave: Paraguay, gobierno de Lugo, movimientos sociales, izquierda paraguaya.

Una de las principales características de la primera década del siglo XXI, en prácticamente toda América Latina, fue el inicio de grandes movilizaciones sociales: desde los grupos tradicionales, sindicatos y campesinos, a nuevos sectores que demostraron tener capacidad tanto de organización como de movilización: indígenas, derechos de la mujer, sin techos, lgbt, ecologistas, entre otros.

En Paraguay también se dio este fenómeno sociopolítico que tiene como una de sus particularidades el carácter multisectorial de sus movilizaciones. El estilo centralista y clientelista del gobierno en Paraguay, a pesar de una constitución de 1992 que trató de modificar eso, sigue imprimiendo desde el poder central un fuerte carácter autoritario, dictadura presidencial, "presicrático" lo denomina Valenzuela (Valenzuela, 2007), obligando a los 
actores sociales a prácticas que orillan la mendicidad. Ante esta lacerante realidad reaccionaron los movimientos sociales

Estos movimientos insisten en una nueva definición de espacios políticos en la sociedad, levantando demandas sectoriales "desde abajo hacia arriba", tratando de modificar el tradicional esquema del Estado clientelista que define las políticas públicas desde el poder de la burocracia estatal. Pero no se puede dejar de mencionar que, como en muchos movimientos en América Latina, el Estado, en algunos casos, domestica y alienta a estos movimientos, aislando sus reclamos y debilitándolos (Gohn, 2010).

En los últimos años los movimientos sociales en Paraguay han dado un salto cualitativo/cuantitativo, entrando a formar parte, aunque aún pequeña, de las fuerzas políticas que influyen en el juego de poder en el país. Todos tratando de encontrar respuestas a la tremenda deuda social que se tiene como país.

Esta "novedad" en la política paraguaya, aparece con un claro perfil de pretender dejar de lado la, por poco tradicional, tesis de que la democracia, casi diríamos la gobernabilidad política, está pendiente de que todo fluya, suceda y se cumpla dentro de los "conductos normales", los caminos estereotipados de lo formal, "la forma correcta" de reclamar y actuar. Justamente el "mejor escenario" para que continúe el despilfarro de la camarilla violenta, corrupta y conservadora. Y el movimiento obrero organizado, lamentablemente, fue uno de los movimientos que mejor ensambló en esa perversa lógica.

\section{Paraguay y las movilizaciones, 15 años de cronología.}

Al reflexionar sobre el momento político actual del Paraguay no podemos dejar de destacar por lo menos tres importantes elementos que grafican y condicionan la lucha de sectores de poder por hegemonizar la vida política en el país:

\footnotetext{
que durante casi 35 años sufrimos una de las dictaduras militares más largas y represoras de Latinoamérica, bajo el gobierno de Stroessner, que sigue marcando profundamente a la sociedad paraguaya, por variadas razones, pero principalmente porque gran parte de la población políticamente activa de hoy vivió esa dictadura, por lo que es difícil presentar un análisis o estudios que no se contaminen rápidamente con la pasión o la falta de objetividad para entender ese largo periodo de tinieblas política.

- Tampoco se puede dejar de lado la pésima calidad de la democracia representativa que se instaló luego del golpe de Estado que derribó a Stroessner -pero no al stronismo-. Una democracia equiparada casi exclusivamente con la realización de elecciones, como acto supremo y representativo del sistema republicano. Autoritarismo, exclusión social, intolerancia y agudización de las desigualdades sociales, son dolorosas marcas de esta fétida democracia post-dictadura.

- $\quad$ Por último tenemos el fenómeno que representó el triunfo de Fernando Lugo en las elecciones presidenciales del 2008, poniendo fin a más de 60 años de gobiernos del Partido Colorado. Una amplia alianza de partidos conservadores, liderados por el
} 
partido liberal - que incluía oficiosamente a sectores del partido colorados- partidos progresistas y organizaciones sociales, logró quebrar algo que parecía casi imposible, derrotar al aparato electoral- prebendario de los colorados (González,2013).

Es decir, estos tres elementos: la dictadura stronista, la pésima democracia y el triunfo de Lugo, ponen el contexto para tratar de analizar/entender la nueva situación política que empezó con el fin del gobierno luguista. El golpe parlamentario del 2012 que lo destituyó cuando faltaba menos de un año para las elecciones presidenciales, y donde un nuevo triunfo del candidato apoyado por el gobierno de Lugo era una posibilidad, marca esta nueva era política paraguaya.

Rescatando el pensamiento de que debemos estudiar la historia, porque los problemas del presente se originaron en el pasado (pues no se trata solo de historia si no de relacionar ese periodo con el presente) tenemos que el proceso de "democratización" ha recorrido un tortuoso, inédito y a la vez complejo camino, por lo que en muchos casos terminamos presentando nuevas interrogantes.

Desde el inicio del siglo XXI, en Paraguay hemos vivido algunos momentos de excepcional protagonismo de los movimientos sociales en la vida política nacional, con dispar resultado para sus protagonistas, pero resaltando el hecho de que en algunos casos se salieron de los marcos "normales" de la discusión política, demostrando la intensidad de las pugnas de los sectores que entraban en confrontación.

A mediados del 2002, un ya consolidado y compacto Frente Social y Sindical (FSS), constituido por sindicatos de trabajadores estatales y privados, organizaciones campesinas, jóvenes, grupos de izquierda y ONGs, jugó sus últimas cartas para frenar las privatizaciones de las empresas estatales de telefonía, agua y electricidad, con masivas y diarias manifestaciones en todo el país. Se produjo una fuerte confrontación con la policía, resultando en innumerables detenciones, heridos y la muerte del manifestante Calixto Cabral, militante de las organizaciones campesinas.

Los parlamentarios, representantes del sector oligárquico paraguayo, no pudieron continuar con el plan, deteniéndose el proceso desde ese momento, pese a esporádicos intentos de tratar de continuar con el proyecto. Fue un punto de inflexión en este tema de resistencia popular a las privatizaciones. Pero también para el FSS. Luego de este fuerte enfrentamiento se disolvió como organización aglutinadora del sector popular, por razones que van mucho más allá de este análisis, quedando como resultado la paralización del plan privatizador y la desaparición del FSS como factor de poder popular. 
Otro hecho que movió la enmarañada política local, se da a mediados del año 2007, con la serie de pedidos de los sindicatos de trabajadores estatales. Se da en medio de un grave descrédito hacia los partidos políticos tradicionales de la más dura derecha política, el Partido Colorado y el Partido Liberal, que traería un año después el triunfo del independiente Fernando Lugo.

Los sindicatos rescataron la lucha por el salario mínimo en nuestro país y tuvo su última gran actuación en el periodo 2007/9, cuando casi 100 sindicatos estatales, de todas las centrales, y entiéndase bien: "todas las centrales", empezaron y consolidaron lo que finalmente fue conocida como la "Campaña Vida Digna”. Los sindicatos involucrados pedían mejores salarios y QUE iiNINGÚN TRABAJADOR DEL ESTADO PARAGUAYO TUVIERA UN SALARIO MENOR AL SALARIO MÍNIMO LEGAL!!!

Esta petición, que dogmáticamente parece absurda, pues el Estado no puede violar "legalmente" la ley del salario mínimo, era válida pues aun así se tenía en ese periodo más de 50.000 trabajadores del sector público que no percibían el salario mínimo. Esta campaña llevó dos años de lucha, movilizaciones y persecuciones, para finalmente lograr sus objetivos.

Una denominada Plenaria de Sindicatos logró, en multitudinarias manifestaciones, unir a trabajadores de la justicia, de las fuerzas armadas, de servicios, maestros, trabajadores de la salud, técnicos, administrativos, profesionales, es decir, todo el universo de trabajadores estatales. Ellos expresaban su descontento por la recuperación salarial que no se modificaba desde hacía 7 años. Para el 2010 lograron incluir en el Presupuesto que ningún trabajador, incluyendo a los maestros, podía ganar menos que el salario mínimo.

Lamentablemente debemos decir que en la actualidad, se tiene nuevamente un retroceso, incluyéndose en el Presupuesto General de Gastos de la Nación, salarios menores que el salario mínimo. Esta posiblemente sea una de las consecuencias de la dejadez de nuestra dirigencia y la división en el campo popular.

\section{Llegada y caída de Lugo}

En ese contexto de crisis de credibilidad de los partidos políticos, que golpeaba fuertemente sobre todo a los dos principales partidos, colorado y liberal, aparece en la ecuación política la figura del monseñor Fernando Lugo, como una tentativa de revivir el papel de gran árbitro de la política nacional, como lo había sido el general Stroessner (González, 2013). Luego de una agresiva campaña, que incluyó acuerdos con el conservador Partido Liberal, con sectores disidentes del Partido Colorado y un conglomerado de partidos de izquierda, logran el triunfo. 
Si bien el gobierno de Lugo tuvo algunos programas que podríamos caracterizar como progresistas, durante los cuatro años que duró su gobierno, sectores como ecología, salud pública, combate a los agrotóxicos, educación, energía, etc, en líneas generales el gobierno siguió la agenda propuesta por los sectores más conservadores del Partido Liberal.

Para el movimiento obrero organizado, la actuación de los líderes de las Centrales Sindicales fue funesta. La puja por ocupar cargos en el gobierno, bajo el pretexto de ser ocupados por representantes de sectores populares, derivó en el objetivo principal y motivo de fuertes disputas internas entre las Centrales.

Aprovechar esa coyuntura favorable para consolidar una tarea de base con formación de cuadros, apuntalando estructuras federativas o fuertes campañas de formación de sindicatos en sectores como supermercados, call centers, maquilas, no fueron prioridades de la dirigencia sindical.

Además de esta falta de acción positiva, se permitió la consolidación de dirigentes con prácticas descaradamente corruptas, patronistas y desmovilizadoras, que hasta hoy siguen con un fuerte activismo en el movimiento obrero organizado.

Una muestra de este rotundo fracaso en reforzar una base social obrera durante este gobierno fue la tibia, o casi nula, reacción de los sindicatos y Centrales ante el golpe de Estado que derrumbó a Lugo del poder. Algunas Centrales intentaron dar una respuesta, pero solo allí percibieron que estaban definitivamente desconectados de sus bases y que la desmovilización había logrado su objetivo. No se tuvo la capacidad, ni la intención, de mejorar poderes alternativos, al contrario, se cayó en la alienación conformista y casi con entusiasmo (Bobbio, 1985, p. 39).

\section{Trabajadores y campesinos}

La llegada al poder del presidente Cartes en el 2013, significó la llegada de un gobierno que tenía marcada la agenda para atomizar y arrancar el movimiento sindical. Hacia mediados del 2015, se dan las declaraciones del Ministro de Industria y Comercio, explicando orgullosamente que el Paraguay tiene uno de los salarios mínimos más bajos de la región, sin que la clase trabajadora organizada de nuestro país atinara a reaccionar, mostrándonos una cruda realidad: la nula capacidad de reacción de las organizaciones sociales ante, incluso, esa amarga burla de las autoridades.

Los trabajadores siempre han luchado por su sustento y el de su familia, en especial desde la consolidación del modo de producción capitalista, en un proceso histórico donde el eje 
era el trabajo y por lo tanto el salario, enfrentando, en distintos periodos, las estratagemas de las clases dominantes. Era a partir de su trabajo que buscaba la dignidad y el bienestar, por eso el papel central del salario (Gramsci, 2007).

En sus declaraciones, el ministro Leite tocaba dos puntos centrales en la consolidación del neoliberalismo actual: los bajos salarios y el gran contingente de desocupados. Mano de obra ociosa, en formación o primer empleo, son algunos de los eufemismos que usa, demostrando que estamos ante un ataque a la esencia del trabajador, el trabajo como sustento de la existencia, pues convengamos que el obrero no tiene alternativa para dejar de ser proletario (Ricfick,1997). Por eso es grave la poca reacción de sus organizaciones, ya en el límite de la complicidad de alguna dirigencia.

Recordemos que desde el inicio de la transición democrática luego de la caída de Stroessner, y el sensacional número de sindicatos que se organizaron, uno de los temas centrales de los empresarios y del gobierno era bajar el salario mínimo, pues se "denunciaba" como el más alto de América. La militancia y la fuerza de la clase obrera organizada fue una traba que el neoliberalismo no logró romper por largos años. El prestigio de las luchas, la claridad en las consignas, la militancia popular y la permanente formación política de las bases, fueron algunas de la claves para resistir.

Entonces no podemos dejar de preguntar, como activistas sociales: ¿Por qué no están movilizados los sindicatos? ¿Dónde están las organizaciones populares? ¿Cómo es que no se están exigiendo explicaciones al ministro? Sobre todo teniendo en cuenta el creciente desmoronamiento salarial y de desempleo que se tiene hoy. Rápidamente habían sido cooptados por el sistema burocrático, desmovilizador y asistencialista, que incorporó a importantes actores sociales claves, en el sistema dirigido por el gobierno. Y allí entra el componente de connivencia y confabulación pagados con cargos, besos o directamente convirtiéndose en traidores a sus iguales.

Los liderazgos sociales, en su gran mayoría, están más preocupados por las elecciones para cargos políticos antes que por las luchas sociales. Esta dejadez de la dirigencia social no sería un problema, pues, de hecho, las luchas sociales van de la mano con las luchas políticas, si no fuera que en las bases, en los sindicatos es donde reina el silencio, no se escuchan los reclamos.

El nivel de conflicto entre el trabajador y el empresario, tiene una relación directa con la capacidad de reacción del trabajador organizado. Cuanto menos conocimientos de la situación, de sus derechos, de su historia, de la comprensión de que cuando más trabaja más 
gana el patrón, menos posibilidades de reacción y fortalecimiento de esa "mística" de la clase obrera en rebelión. Porque así como el trabajador no tiene opción, tampoco el empresario puede dejar de lado la explotación: la dinámica empresarial del sistema le obliga a agudizar y perfeccionar su explotación, bajando salarios, eludiendo la seguridad social, empleando jóvenes, etc.

La falta de formación, información y práctica en las bases es alarmante, pues ya vimos, con varios ejemplos a lo largo de nuestra historia social, que esa falta de intuición de las bases del contexto de explotación, producto de la alta y perfeccionada alienación de nuestra sociedad de consumo, ha llevado al descabezamiento de grandes y memorables luchas en nuestro país.

\section{Movimientos sociales y movilización}

Ahora bien, en los últimos años se da la movilización de otros sectores sociales, en consonancia con el mismo fenómeno en América, que reclaman una sociedad más justa, menos discriminativa.

En el 2016 apareció con recargada y llamativa fuerza el movimiento feminista, realizando una movilización que auguraba una nueva fuerza social. El 8 de marzo de este año, día internacional de los derechos de la mujeres, este movimiento realizó una movilización multitudinaria, colorida, creativa y con fuerte carácter político.

Una movilización que ante la recatada y tenazmente conservadora sociedad paraguaya fue un tremendo hecho político. Ese compacto grupo de jóvenes pidiendo más libertad, más tolerancia, más protagonismo en todos los ámbitos, dejó a los políticos, y a muchos activistas sociales, en total estado de shock, casi sin poder creer lo que acontecía antes sus narices y lo que pasaban por televisión.

Si bien este movimiento de reclamo de derechos para las mujeres no puede tomarse como el inicio de una línea en la política paraguaya, lo que sí es indudable, es que marcó en la agenda de los líderes políticos un nuevo e inevitable tema. Además, la conformista élite en nuestra adormecida política, quedó asustada por la capacidad de movilización, alcance popular y aceptación entre los y las jóvenes de sus consignas. El año 2017 está marcado por incesantes movilizaciones derivadas de esta llamada germinal, que también tuvo la virtud la renovar en gran medida a una gastada y poco efectiva dirigencia histórica del feminismo, irrumpiendo una nueva y activa militancia.

Otro sector que se muestra inusitadamente activa desde el 2015 es el de los estudiantes, tanto secundarios como universitarios. En el sector universitario, ante reclamos casi baladíes a 
las autoridades, y sobre todo por la respuesta cargada de soberbia y autoritarismo, se generó un movimiento de reclamo que fue creciendo exponencialmente ante el asombro de las enquistadas autoridades universitarias. En menos de 15 días toda la Universidad Nacional de Asunción (UNA) se declara en paro y el campus universitario queda bajo total control de los sublevados estudiantes.

Este movimiento conocido como UNA NO TE CALLES, logró en dos meses algo que parecía imposible, destartaló una fuerte y corrupta camarilla que dirigía la Universidad Nacional, logró las renuncias del Rector de esta (un verdadero hombre fuerte del partido colorado), de varios decanos en distintas facultades. Se logró imponer una Asamblea Universitaria que estudiaría el antiguo estatuto de la universidad y como broche final, el procesamiento y prisión del autoritario, ultraconservador Rector de la Universidad, que hasta hacía dos meses era el todopoderoso de la UNA.

Pero el movimiento no se detuvo en eso y siguió hasta hace unos meses, denunciando corrupción, ocupando facultades, derribando decanos y desarticulando roscas corruptas y con viejas prácticas de clientelismo político.

Políticamente tuvo un fuerte impacto en la ciudadanía. La solidaridad fue inmediata y sostenida, cuando varios sectores se hicieron cargo de mantener la alimentación de los chicos y chicas que ocupaban el Campus, que se veían hostigados por las autoridades, fiscales y las fuerzas represivas.

También los estudiantes secundarios se mantuvieron muy activos durante este mismo periodo. Con marchas contra la política del ministerio de Educación, convocados por las dos principales federaciones que los aglutinan, desde hace tres años no dan respiro a las autoridades. Es que son autoridades poco proclives a negociar. Lograron la renuncia de la ministra de educación, verdadero buque insignia del gobierno, así como aumentos sucesivos del presupuesto destinado a ese ministerio, todo en medio de movilizaciones y ocupaciones de colegios.

Un tercer sector que se mostró muy activo es el de los campesinos. Al mismo tiempo que el movimiento sindical paraguayo entraba en fuerte reflujo, apareció con fuerza el protagonismo de las organizaciones campesinas. El Paraguay sigue con el alto índice de desigualdad donde el $85 \%$ de las tierras están en manos de $3 \%$ de propietarios, según los datos del último Censo Agropecuario Nacional del Ministerio de Agricultura y Ganadería del 2008.

Desde el año 2015, y ante la falta de respuestas del gobierno a la difícil situación del sector que sostiene la economía basada en la agricultura familiar: amenazada, castigada y 
desplazada por los cultivos de los agronegocios, los campesinos se vieron en la necesidad de volver a ser protagonistas de las luchas políticas. Las deudas y los castigos de la naturaleza reciamente alteradas por los cultivos de productos genéticamente modificados, sumieron en una extrema pobreza a numerosas familias campesinas. ${ }^{1}$

En dos grandes movilizaciones campesinas, una en el 2016 y otra en julio de 2017, junto a cooperativistas, lograron sitiar el centro histórico de Asunción por más de un mes, creando un caos en la vida administrativa de la capital. La asustada oligarquía paraguaya: ganaderos, sojeros e industriales, reaccionó con virulencia en los medios de comunicación que están en sus manos.

La ocupación campesina, y por sobre todo la solicitud de un subsidio estatal para la agricultura familiar, similar al dado a los industriales, sojeros y transportistas, llevaron a una polarización de opiniones en la sociedad paraguaya. Quedó como hecho resaltante que los sectores más duros de la política local, asumieran pública y enérgicamente un rechazo al intento de sostener, desde el Estado, políticas que potencien la producción alternativa campesina, dejando en claro su odio visceral a todo proyecto que intente enfrentar al modelo extractivista neoliberal vigente en el país.

\section{Y el movimiento obrero organizado?}

Como hemos dicho, el movimiento sindical entró en un fuerte reflujo a partir de las jornadas del 2002 contra las privatizaciones. Con esporádicas apariciones sobre temas puntuales, se puede decir que no pudo recuperar el protagonismo que mantuvo en la última década del siglo XX.

Con la llegada de Lugo a la presidencia, los partidos y grupos de izquierda apostaban al fortalecimiento de las organizaciones populares, sindicatos, campesinos, vecinales, entre otros. Sin embargo, ganó en definitiva la tesis de que la vía administrativa lograría fortalecer a las organizaciones, se lograrían mejores derechos y hasta una Reforma Agraria (Hetherington, 2015). Lo que realmente pasó fue que rápidamente estos mismos sectores fueron fagocitados por la lógica del poder estatal. La ocupación de cargos en ministerios y demás organismos estatales se convirtió en el verdadero objetivo, con la retorcida argumentación de articular desde allí la participación de sectores progresistas en las próximas elecciones.

\footnotetext{
${ }^{1}$ Los datos estadísticos oficiales, en 2016, el $10 \%$ de la población sobrevive en la extrema pobreza y el $30 \%$ en la pobreza

Barbarói, Santa Cruz do Sul, n. 58, p.<218-229>,jan/jun 2021
} 
El Golpe de Estado que derribó a Lugo encontró a estos sectores progresistas tan divididos, desmovilizados y con prácticamente nula capacidad de conducción en las bases, que aun mantenían el apoyo a Lugo. Se pagó caro el haber desechado el poder de las movilizaciones como sostén del gobierno, real y poderoso argumento que fue poco alentado y menos aun utilizado por el sector progresista del gobierno luguista.

La instalación de los gobiernos luego del golpe, solo sirvió para acentuar ese desalentador escenario para los sectores sociales. De entre estos, los sindicatos fueron los que menos presencia tuvieron en el escenario político-social post golpe. La posición cada vez más conciliadora y no transformadora, olvidando un papel fundamental de los sindicatos en la sociedad (Gohn, 2010), en momentos en que se manifestaba un acelerado descrédito en los representantes políticos, que supondría un estadio ideal y que podría haber sido aprovechado por los sindicatos.

Las últimas movilizaciones de jóvenes y campesinos, han logrado instalar el debate, y la polémica, en relación a temas como la "democracia formal", la pobreza, la deuda social, la violencia, entre otros temas. La coyuntura es favorable para desarrollar propuestas de cambios sociales desde el sector de los trabajadores. En plena sociedad sostenida en base a la alta tecnología, aparecen un número cada vez mayor de seres desesperados y sin futuro, que solo encuentra alternativa en la marginalidad y el crimen, para este segmento, solo los trabajadores organizados podrían tratar de proponer alternativas, ya que la élite oligárquica a cargo del gobierno, solo responde con represión, violencia y más discriminación.

El gobierno de Cartes, desde que asumió, accionó una política anti-sindical muy bien articulada. Con asesores sindicales, ex-dirigentes sindicales, diseñando políticas desmovilizadoras y represoras, lograron golpear a las ya debilitadas fuerzas obreras organizadas. La militancia sindical hoy se desarrolla prácticamente en la clandestinidad, con trabajadores despedidos inclusive antes de la conformación del sindicato, producto de la información suministrada por delatores infiltrados. Esta situación de represión selectiva, con fuerte tufo fascista, obliga a la dirigencia a tratar de encontrar nuevos métodos de organización, pero que hasta hoy no están dando resultados efectivos.

En el 2014 fue la última huelga general convocada por las centrales obreras. Si bien tuvo un acatamiento aceptable en sectores como transporte, electricidad, educación, que logró paralizar en gran medida la capital del país, se pudo constatar que era un esfuerzo muy desgastante, tanto en la militancia como en lo económico, y que difícilmente podría sostener con ese esquema un enfrentamiento al recién llegado gobierno del presidente Cartes. El apoyo 
y participación de grupos de estudiantes, mujeres y ecologistas dio un marco de frescura a la jornada de protesta, que no logró tapar la clara ausencia de un real liderazgo en las bases obreras.

El abandono de las prácticas de trabajo de base, formación de cuadros, consignas claras, sobre todo desde las Centrales Obreras, y la falta de alternativas para enfrentar el neo sistema represivo, muestran que gran parte de la dirigencia sindical, apegada a prácticas clientelistas y burocráticas, no pueden invocar un real liderazgo. Sin embargo, las nuevas dirigencias surgidas en los últimos meses más ligados a grupos de izquierda, han logrado transmitir alguna expectativa. Apoyo a las tomas de colegios, a las movilizaciones campesinas y de universitarios, consignas a favor de mayores recursos en el presupuestos nacional, y campañas de organización y articulación para las luchas anuales por el presupuesto en el parlamento, son algunas de las acciones que podrían representar alguna alternativa popular.

No es nada nuevo decir que luchar por la justicia social en el mundo del trabajo es urgente y que por sobre todo demanda un liderazgo y agudeza de pensamiento colectivo, no solo de los directivos, sino de intelectuales, militantes, afiliados a los sindicatos, etc. Pero la gran pregunta es: ¿será que quienes están tomando la posta del liderazgo popular estarán a la altura del reto? ¿O nuevamente los veremos perderse en los laberintos del clientelismo, la burocracia y el sectarismo político, como fueron las experiencias de los últimos años, que fácilmente se puede confundir con verdadera traición a la clase obrera?

Todo parece indicar, o será más un anhelo quizás, que sí se consolida este nuevo liderazgo, se podría apuntalar una alternativa que impulse importantes avances en la historia social del país, porque, como dice el dogma socialista, si no se organizan los trabajadores, seguirán siendo simple materia prima para la explotación capitalista.

\title{
PARAGUAY, THE REBIRTH OF A CONTAGIOUS UTOPIA?
}

\begin{abstract}
The article analyzes the political mobilizations in Paraguay, starting in the 2000s, with greater attention to the relationship between social movements and the government of Fernando Lugo (2008 - 2012). Among the aspects highlighted in the text is that social movements in Paraguay had a significant role since the 2000s. Since Lugo's arrival in the national government, however, it was observed that the actions of the leaders of the Trade Union Centrals began to prioritize government positions. In other words, the parties and groups of the left are committed to strengthening popular organizations, unions, and social movements based on the assumption that the administrative route could strengthen organizations and guarantee greater gains in rights. What happened, however, was that the leaders were quickly co-opted by the logic of state power and the occupation of positions became the main objective.
\end{abstract}

Keywords: Paraguay, government of Lugo, social movements, Paraguayan left. 


\section{REFERÊNCIAS}

BOBBIO, Norberto. Diccionario de política. Siglo XXI. México. 1985.

GONZÁLES BOZZOLASCO, Ignacio. La encrucijada del cambio. Novapolis. Asunción. 2013.

GOHN, Maria da Glória. Movimentos Sociais e Redes de Mobilizações Civis no Brasil Contemporâneo. Petrópolis, RJ: Vozes, 2010.

GRAMSCI, Antonio. L'Ordene Nuovo-Selección de artículos 1919-1922. Germinal. Asunción. 2007.

HETHERINGTON, Kregg. Auditores campesino, CERI-Servilibro, Asunción. 2015.

RICFICK, Jeremy. El fin del trabajo. Paidos. Buenos Aires. 1997.

VALENZUELA, Esteban. Aproximación al concepto de cooptación política: la maquinaria presicrática y sus formas Polis 40. Publicado el 17 mayo 2015. http://polis.revues.org/10834.

Data de recebimento: $21 / 01 / 2020$

Data de aceite: $25 / 01 / 2020$

\section{Sobre o autor:}

Jorge Coronel Prosman atuou na liderança do movimento operário paraguaio relacionado ao setor elétrico, tendo sido docente da Escola Sindical Rafael Barrett e coordenador da Fundación Generación. Mestre em História da Filosofia, fez graduação em Administração Agrária e Especialização em Economia Social. Já há algum tempo se dedica ao registro da história dos movimentos populares e de trabalhadores no Paraguai, sendo autor de livros sobre o tema, dentre os quais: "Itaipú e a História dos Trabalhadores: 15 anos de luta, conquista e resistência", "Soledad Barrett e as traições na luta armada", "SITRANDE, 20 anos de luta, fazendo história", "O Último dos bondes: ou como o estronismo destruiu o sindicato do setor elétrico". Endereço Eletrônico: jorlita@hotmail.com 